\title{
Obesity and atherosclerosis: the exosome link
}

\author{
Allison B. Reiss, Daniel S. Glass, Iryna Voloshyna, Amy D. Glass, Lora J. Kasselman, Joshua De Leon \\ Department of Medicine and Research Institute, NYU Long Island School of Medicine, Mineola, NY 11501, USA.
}

Correspondence to: Dr. Allison B. Reiss, Department of Medicine, NYU Long Island School of Medicine, 101 Mineola Boulevard Suite 4-004, Mineola, NY 11501, USA. E-mail: allison.reiss@nyulangone.org

How to cite this article: Reiss AB, Glass DS, Voloshyna I, Glass AD, Kasselman LJ, De Leon J. Obesity and atherosclerosis: the exosome link. Vesse/ Plus 2020;4:19. http://dx.doi.org/10.20517/2574-1209.2020.04

Received: 16 Jan 2020 First Decision: 2 Mar 2020 Revised: 15 Apr 2020 Accepted: 28 Apr 2020 Published: 12 Jul 2020

Academic Editor: Nicola Ferri Copy Editor: Jing-Wen Zhang Production Editor: Tian Zhang

\begin{abstract}
Obesity is a global public health issue with serious health consequences and rising prevalence. It is a risk factor for a broad range of diseases, particularly atherosclerosis and cardiovascular disease. Long-term weight loss is difficult to achieve, even with diet, life-style changes and anti-obesity drugs. The causes of the association between obesity and atherosclerotic cardiovascular disease are the subject of ongoing investigation. It is known that a chronic surplus in nutritional intake results in expansion and remodeling of adipose tissue, leading to chronic inflammation. Lipid overloaded adipocytes secrete pro-inflammatory adipokines and other mediators that produce this inflammatory state that may in turn, promote atherosclerosis, which is considered an inflammatory disorder. This review discusses the potential role of exosomes from adipose tissue in accelerating atherosclerosis in the setting of obesity. Exosomes are small membrane-bound vesicles that circulate in body fluids and are important participants in intercellular communication both locally and at a distance. They can transfer their cargo of protein, DNA, RNA and microRNA between cells, thus impacting cellular function and signaling. Adipose tissue-derived exosomes may be involved in heightening of the atherogenic environment and, if so, suggests a therapeutic target for the treatment and prevention of cardiovascular complications of obesity.
\end{abstract}

Keywords: Obesity, atherosclerosis, adipocyte, macrophage, exosome

\section{INTRODUCTION}

Atherosclerotic cardiovascular disease (ASCVD) remains the leading cause of morbidity and mortality worldwide ${ }^{[1-3]}$. Obesity increases the risk of ASCVD and death even after accounting for other known risk factors such as dyslipidemia, smoking, and hypertension ${ }^{[4]}$. The underlying mechanisms that produce the added harmful effects of obesity are poorly understood. Elucidating the mechanisms behind differences between obese individuals with and without atherosclerosis ${ }^{[5,6]}$ could reveal therapeutic targets for treating

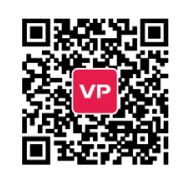


the harmful cardiovascular consequences of obesity as an alternative or adjunct to weight-loss programs, which are known to have limited long-term success.

Adipose tissue acts as an active metabolic endocrine organ that releases not only hormone-like adipokines and inflammatory cytokines, but also cargo-carrying vesicles such as exosomes that may be considered a form of adipokine that contributes to the development of atherosclerosis ${ }^{[7-10]}$.

Adipose tissue in obese subjects is inflamed as compared to lean subjects and displays greater macrophage infiltration ${ }^{[11]}$. In the obese state, adipose tissue can no longer accommodate excess energy stores and among the maladaptive changes that occur are infiltration by a variety of inflammatory immune cells that interact with adipocytes to promote chronic inflammation ${ }^{[12]}$. Atherosclerosis progression is driven by inflammation and the pro-inflammatory environment fostered by excess adiposity is thought to be a critical link between obesity and ASCVD ${ }^{[13,14]}$. Sequential steps in atherosclerosis are: circulating monocyte adhesion to endothelium, penetration through the compromised barrier, differentiation into macrophages and excessive uptake of lipids ${ }^{[15]}$. Each of these steps may be vulnerable to interference by exosomes. This review will discuss the connection between adipose tissue and atherosclerosis and the potential role of exosomes in communicating atherogenic signals from fat depots to the arterial wall. Understanding these relationships may be invaluable in the understanding, prevention and treatment of ASCVD.

\section{ATHEROSCLEROSIS, INFLAMMATION AND LIPIDS}

Atherosclerosis is a process that takes place in the arterial wall and its earliest stage involves a breach of the vascular endothelium by monocytes, which settle in the subendothelial space and become macrophages ${ }^{[16]}$. In an inflammatory environment, these macrophages in the subendothelial intima may exhibit impairment of cholesterol efflux, which leads to intracellular accumulation of modified low-density lipoprotein (LDL) and subsequent formation of plaque-forming lipid-rich foam cells ${ }^{[17,18]}$. Macrophages may become classically or alternatively activated to the M1 or M2 phenotype, respectively. During atherogenesis, monocytes enter the atheroma and differentiate into the M1 macrophage subtype and it is these M1 macrophages that play a crucial role in the initiation and progression of atherosclerosis ${ }^{[19]}$. M1 macrophages are considered pro-atherogenic because they easily transform into cholesterol-overloaded foam cells while the M2 subtype is less atherogenic and has a lesser propensity to form foam cells. M2 macrophages are associated with tissue repair and are enriched in regressing plaques ${ }^{[20]}$.

Macrophage cholesterol homeostasis is a delicate balance among influx, endogenous synthesis, esterification/hydrolysis and efflux ${ }^{[21]}$. The low grade chronic inflammation associated with obesity is a likely driver of dysregulated macrophage cholesterol homeostasis. It has also been shown to adversely affect expression of the proteins responsible for cholesterol influx and efflux by our group and others ${ }^{[22-29]}$.

A variety of cytokines may stimulate the atherosclerotic process, including interferon (IFN) $-\gamma$, tumor necrosis factor (TNF)- $\alpha$, and interleukin (IL)- $1 \beta^{[30,31]}$. TNF- $\alpha$ and IL- $1 \beta$ induce cytokine and adhesion molecule expression and also encourage the migration of vascular smooth muscle and endothelial cells ${ }^{[32,33]}$. IFN- $\gamma$ promotes foam cell formation ${ }^{[25,34]}$.

One of the most compelling clinical challenges of our time is the increasing prevalence of obesity and its detrimental effects on the cardiovascular system. Obesity influences inflammation and the pathophysiological processes involved in atherosclerotic disease development ${ }^{[35]}$. Obesity and overweight are accompanied by unfavorable blood lipid profile patterns ${ }^{[36,37]}$. Dyslipidemia is a major risk factor for coronary artery disease. Among obese patients, the estimated prevalence of hypertriglyceridemia is twice as high as in non-obese individuals ${ }^{[3]}$. In addition, the atherogenic combination of hypertriglyceridemia with high LDL and low HDL is more prevalent in obese and overweight patients ${ }^{[39,40]}$. Unfortunately, high 


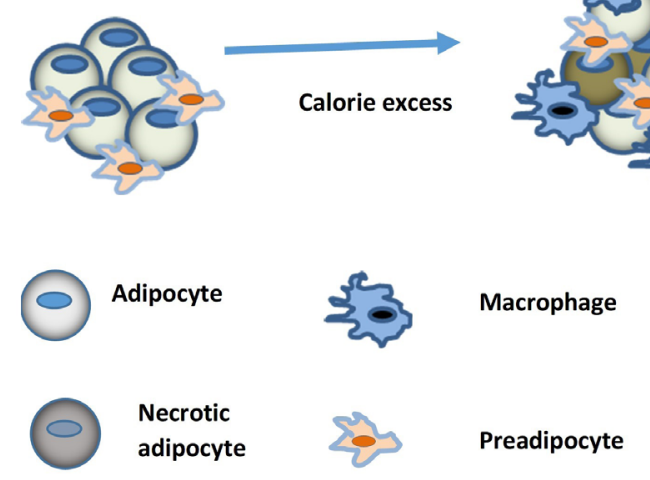

Figure 1. Change in white adipose tissue with unhealthy weight gain. Excess calorie intake results in dysfunctional adipose tissue characterized by a chronic inflammatory state with macrophage infiltration and phenotypic switching, inflammatory cytokine secretion, adipocyte necrosis, reduced insulin sensitivity and hypoxia

residual ASCVD risk remains even when LDL cholesterol is reduced to target levels and comorbidities are optimally treated ${ }^{[41-44]}$. Pathological processes within the arterial wall may continue despite statin and other pharmacologic therapies. The standard lipid profile would not be sensitive to this type of regional arterial process because it measures liver metabolism of cholesterol and other systemic effects not localized at sites of atherosclerosis. Lipid dyshomeostasis at the cellular level within the artery is not reflected.

\section{ADIPOSE TISSUE}

Adipose tissue is not simply an inert tissue for storing excess energy and a thermal insulator. It is an active endocrine organ at the center of metabolic dysfunctions associated with obesity ${ }^{[45,46]}$. Adipose tissue contains a variety of cell types including adipocytes, preadipocytes, pericytes, fibroblasts, endothelial cells and macrophages. The biology of adipose tissue is complex as it can exist in different forms and is classified as white adipose tissue (WAT) or brown adipose tissue (BAT) based on morphology and function ${ }^{[47]}$. WAT holds energy in the form of triglycerides as a buffer against starvation and is the largest free cholesterol reservoir in the body, while BAT is more energetically active, with a greater number of mitochondria and higher energy production ${ }^{[48]}$. Mature WAT adipocytes each contain a single large lipid droplet. Obesity induces changes in WAT leading to increased lipolysis, insulin resistance, adipocyte hypertrophy and regions of hypoxia [Figure 1]. WAT secretes into the bloodstream many adipokines, which are bioactive molecules that are thought to contribute to the inflammatory milieu, thus promoting atherosclerosis ${ }^{[49-52]}$. However, anti-inflammatory treatments have failed to reduce ASCVD, indicating that factors other than inflammatory mediators are involved in the interplay between adipose tissue and blood vessels ${ }^{[3,54]}$. Exosomes may be one of the links that contribute towards development of ASCVD in obesity ${ }^{[55]}$.

Over the last few years, BAT has also been recognized as a potential therapeutic target in the prevention of atherosclerosis ${ }^{[56-58]}$. BAT consumes energy and generates heat through the action of uncoupling protein 1 , which disconnects the electron transport chain from ATP synthesis ${ }^{[59]}$. The distribution of brown adipocytes in the body maximizes the cytoplasmic-lipid interface, making their involvement in fatty acid metabolism more effective than white adipocytes. In mice, brown adipocyte-derived endocrine factors significantly diminish body weight via elevation of oxygen consumption and decrease in total body fat mass ${ }^{[60]}$. Activation of endogenous brown adipocytes induces intracellular lipolysis of triglycerides and 


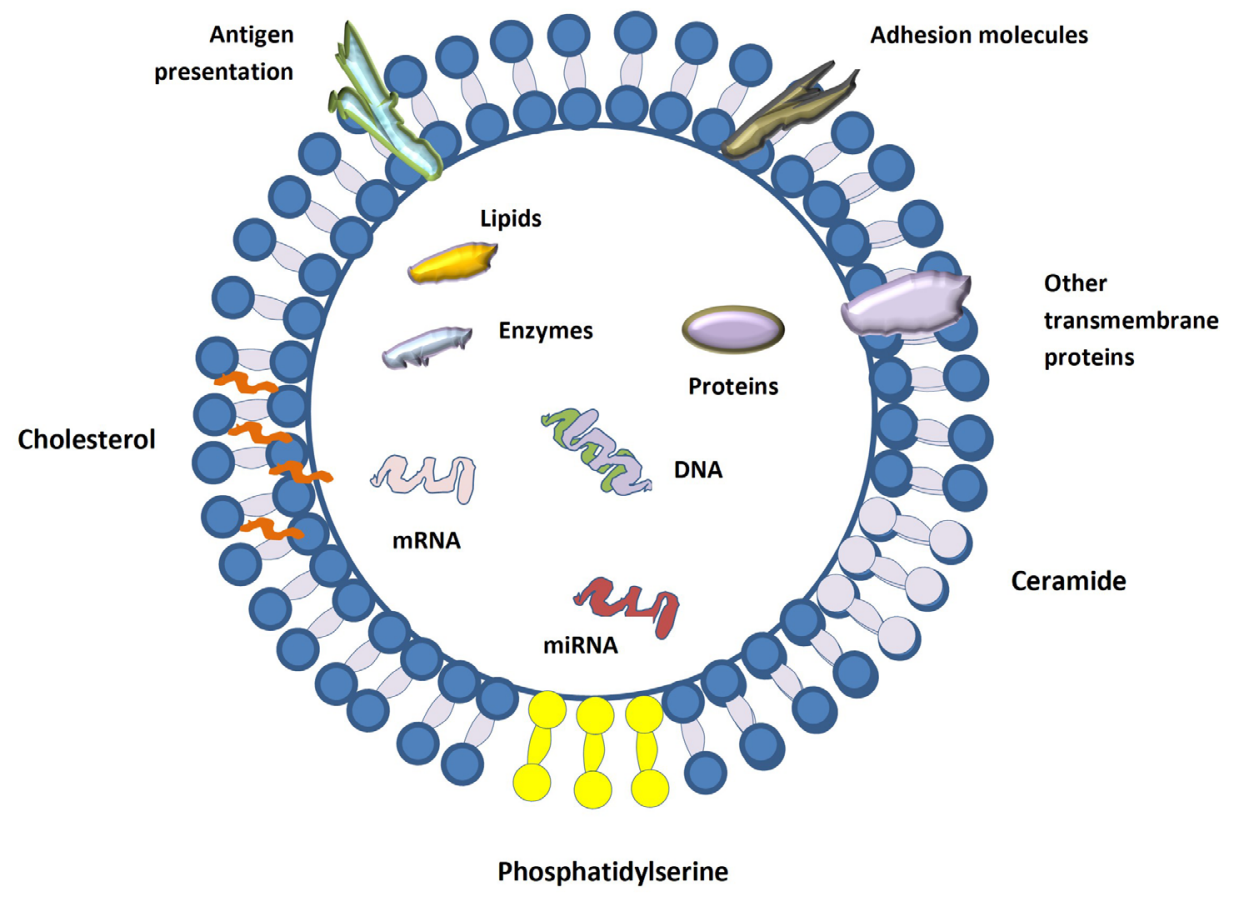

Figure 2. Exosome structure. Exosomes are microvesicles delineated by a membrane enriched in phosphatidylserine and contain DNA, mRNA, miRNA, proteins and lipids

thus, leads to release of fatty acids and glycerol in the cytoplasm with reduced plasma triglyceride levels and obesity ${ }^{[61,62]}$.

Adipose tissue is a key organ that controls lipid metabolism and energy distribution, as well as regulation of endocrine function related to cardiovascular disease. Endocrine functions of adipose tissue are mostly attributed to their ability to secrete adipokines, hormones and cytokines that regulate energy homeostasis and satiety ${ }^{[7]}$. There are over 600 known adipokines but the most well-studied are the anti-inflammatory adiponectin, which is decreased in obesity, and leptin, which is secreted mostly by WAT and is present unbound in the circulation at higher levels in obesity ${ }^{[63-65]}$. Adipokines are carried by human adipocyte exosomes and leptin has been detected in mouse serum exosomes while adiponectin has been found in rat adipose tissue exosomes ${ }^{[6-68]}$.

\section{EXOSOMES AND ADIPOCYTE-DERIVED EXOSOMES}

Exosomes are a type of extracellular vesicle with a size of 30-150 nm and a specific density of $1.13-1.21 \mathrm{~g} / \mathrm{mL}$. They are found in blood and other biological fluids. Exosomes are released into the extracellular space when multivesicular bodies fuse with the cellular plasma membrane ${ }^{[69,70]}$. Exosomes carry nucleic acids such as microRNA (miRNA), messenger RNA (mRNA) and mitochondrial DNA as well as proteins and lipids [Figure 2]. These exosome components are encased in a phospholipid membrane rich in ceramides, cholesterol and sphingomyelin, often with high phosphatidylserine content ${ }^{[71-73]}$. Exosomes help mediate signal transduction and provide a means for cell-to-cell communication over a distance and between organ systems ${ }^{[74]}$. Signaling pathways can be impacted by exosomes through the miRNAs they carry. miRNAs are small non-coding RNAs that negatively regulate gene expression by impeding translation or inciting instability of complementary mRNA targets, thus inhibiting protein formation ${ }^{[75]}$. Exosomes carrying miRNAs can be taken up via endocytosis or pinocytosis into recipient cells ${ }^{[76]}$.

It should be noted that there are different circulating particles in the blood and bodily fluids, collectively known as extracellular vesicles. These are heterogeneous in size and include not only exosomes, but also 
microparticles, which are larger in size but have similar composition and structure ${ }^{[77]}$. It is difficult to differentiate between these, but we have tried to confine this discussion as much as possible to exosomes. The appearance of adipose-derived exosomes in the circulation has been documented in humans and mice ${ }^{[78,79]}$. Adipocyte-derived exosomes may be considered a form of adipokine ${ }^{[79]}$. In mice, adipose tissue is an important source of circulating exosomal miRNAs in the obese state ${ }^{[79]}$. The miRNA cargo of adipocytederived exosomes may influence pathways involved in obesity and atherosclerosis ${ }^{[80-82]}$. Many miRNAs have been shown to be differentially expressed in obese adipocyte exosomes, compared to lean adipocyte exosomes in both mouse and human ${ }^{[83]}$. Adipocyte-derived exosomes affect insulin resistance ${ }^{[84]}$. Mice with adipose tissue-specific knockout of Dicer, a large multi-domain ribonuclease enzyme responsible for the biogenesis of miRNA, produce exosomes with low miRNA content and exhibit a form of lipodystrophy marked by loss of WAT and whitening of BAT, as well as insulin resistance and dyslipidemia ${ }^{[79,85]}$. When WAT from wild type mice is transplanted into Dicer knockouts, circulating miRNAs are restored and glucose tolerance improves. Phenotypic change of cultured Dicer knockout brown preadipocytes to a white adipocyte-like state was modulated by specific miRNAs miR362, miR365 and miR346. Exosomes from adipose tissue macrophages of obese mice confer poor glucose tolerance and insulin resistance when transferred to lean mice ${ }^{[86]}$. A comparison of miRNA content of adipose tissue macrophage exosomes of obese versus lean mice showed that miR155 was much more abundant in exosomes from obese mice and this miRNA was shown to inhibit insulin signaling via downregulation of peroxisome proliferator-activated receptor $\gamma$, a key regulator of adipocyte differentiation, glucose and lipid metabolism. Mice with knockout of miR155 fed a high fat diet for 12 weeks exhibited less obesity-induced glucose intolerance and insulin resistance, compared to wild type mice on a high fat diet. When wild type bone marrow was transplanted into miR155 knockouts, glucose tolerance and insulin sensitivity were impaired with feeding of high fat diet.

In mice, fibroblast growth factor (FGF)-21, a member of the FGF family with hormone-like actions that regulates glycolipid metabolism, can be downregulated in liver by miRNA29b carried in exosomes ${ }^{[87,88]}$. This effect of adipose tissue exosomes on FGF21 may be pro-atherogenic since FGF21 is considered atheroprotective and improves the cardiometabolic profile in obesity and diabetes ${ }^{[89]}$. Exosomes released from adipose tissue of obese mice and injected into wild type mice induce activation of monocyte differentiation to macrophages in the latter, causing inflammatory cytokine production through the tolllike receptor (TLR) 4 pathway ${ }^{[90]}$. Macrophages in atherosclerotic lesions express TLRs, including TLR4, a type of pattern recognition receptor that is known to mediate inflammatory activation and TLR4-deficient mice are protected from forming atherosclerotic lesions ${ }^{[91]}$. Both pro-inflammatory/pro-atherosclerotic (M1) and anti-inflammatory (M2) macrophage phenotypes were induced by adipose tissue exosomes. The obese mouse adipose exosomes also caused insulin resistance in wild type mice. Mouse exosomes derived from visceral adipose tissue cause foam cell formation in a mouse macrophage cell line, likely due to inhibition of cholesterol efflux due to decreased expression of ATP binding cassette transporter (ABC) A1 and ABCG1, reverse cholesterol transport proteins that are needed to prevent lipid overload ${ }^{[92,93]}$. Adipocyte exosomes affect macrophage function in humans as well ${ }^{[94]}$.

Exosomes from adipose tissue may also influence vascular endothelial cells, but this is not as well-studied as in macrophages. Vascular endothelial cells take up adipose tissue exosomes and it is postulated that obese adipose tissue may secrete exosomes with pro-inflammatory cargo that could then activate the endothelium $^{[95-97]}$. Confirmation of the interaction of adipocyte exosomes and vascular endothelium awaits further study.

Pericytes are pluripotent contractile cells embedded in the basal membrane surrounding endothelial cells that directly interact with endothelium, and are increasingly recognized for their involvement in atherosclerosis ${ }^{[98,99]}$. At this time, there is no data on adipocyte exosome effect on pericytes or pericyte- 
endothelial interaction, but it is known that pericytes can affect the endothelium through exosomes and so, adipocyte-to-pericyte communication via exosomes may merit investigation ${ }^{[100]}$.

Both proteins and miRNAs within exosomes may be involved in their effects. Adipocyte exosomal miRNAs can influence macrophages resident within adipose tissue towards an inflammatory direction and can be delivered to the vasculature where in vitro studies have shown that they induce pro-atherogenic changes in macrophages ${ }^{[101,102]}$. One example is miR-34a, which is expressed at a higher level in adipose tissue of obese compared to lean mice and also, in obese compared to lean humans ${ }^{[101]}$. In mice, miR-34a downregulated Kruppel like factor 4, a transcription factor that drives M2 macrophage polarization, and this resulted in less M2 and more M1 macrophages in adipose tissue. In human studies, the number of circulating adipocytederived extracellular vesicles has been found to correlate with insulin resistance in obese subjects and with serum triglyceride levels ${ }^{[103,104]}$.

\section{CONCLUSION}

The link from obesity to adipose tissue dysfunction to adipose-derived exosome influence on atherosclerosis is only being explored now. Many of the experiments cited in this review utilize particles produced in vitro and then introduced into in vivo animal models. Even though this is a useful initial approach towards understanding the effects of different particles, it does not provide cause-and-effect evidence of what is occurring in humans in vivo. Rather, it guides direction for future studies.

Exosomes from adipose tissue are formed by inward budding of the limiting membrane of late endosomes, fuse with the plasma membrane and released into the blood or extracellular fluid ${ }^{[105]}$. We now have the technology to isolate exosomes of adipocyte origin directly from the blood for analysis of their content and sequencing of their miRNAs ${ }^{[105]}$. As more miRNA sequences are found to affect specific signaling pathways, we can expect further elucidation of how they impact multiple aspects of atheroma formation and maturation. A working hypothesis is that obesity induces chronic low-grade inflammation within adipose tissue leading to specific changes in exosome cargo from both adipocytes and resident macrophages. The miRNA and protein in these exosomes enter the circulation, reach the blood vessels and influence the endothelial monolayer, macrophages and the stability of the plaque. The adipocyte exosomes may also indirectly foster atherosclerosis by playing a role in insulin resistance and type 2 diabetes. Exosomes from adipose stem cells may exert protective, anti-inflammatory effects on macrophages, suggesting a means to develop countermeasures to the pro-inflammatory influence of adipose tissue ${ }^{[106]}$. While it is clear that macrophages are integral to the atherosclerotic process, their precise role is still uncertain. Macrophages may be part of the formation of a plaque, or they may be attracted to lipid deposits within the arterial wall and act as phagocytes absorbing these lipids, as has been observed in early atherosclerotic changes, and may participate either way ${ }^{[107]}$. Whatever the context, the effect of exosomes on macrophages in atherosclerosis is worthy of further study. Knowledge of processes through which adipose tissue exosomes may accelerate atherosclerosis progression would open up an opportunity to mitigate these negative effects, even in persons who do not lose weight. One such approach would be to design and produce exosomes harboring antagomirs to neutralize undesirable and overexpressed miRNAs ${ }^{[108]}$.

\section{DECLARATIONS}

\section{Acknowledgments}

This work was supported by the Elizabeth Daniell Research Fund. We thank Robert Buescher for his generous support.

\section{Authors' contributions}

Researched data for the article, discussed its content, and wrote, reviewed, and edited the manuscript: Reiss $\mathrm{AB}$, Kasselman LJ, De Leon J 
Researched data for the article, discussed its content, and edited the manuscript: Voloshyna I, Glass DS, Glass AD

\section{Availability of data and materials}

Not applicable.

\section{Financial support and sponsorship}

None.

\section{Conflicts of interest}

All authors declared that there are no conflicts of interest.

\section{Ethical approval and consent to participate}

Not applicable.

\section{Consent for publication}

Not applicable.

\section{Copyright}

(c) The Author(s) 2020.

\section{REFERENCES}

1. Dalen JE, Alpert JS, Goldberg RJ, Weinstein RS. The epidemic of the 20(th) century: coronary heart disease. Am J Med 2014;127:807-2.

2. Wong ND. Epidemiological studies of CHD and the evolution of preventive cardiology. Nat Rev Cardiol 2014;11:276-89.

3. Benjamin EJ, Virani SS, Callaway CW, Chamberlain AM, Chang AR, et al. Heart disease and stroke statistics-2018 update: a report from the American Heart Association. Circulation 2018;137:e67-492.

4. Whitlock G, Lewington S, Sherliker P, Clarke R, Emberson J, et al. Body mass index and cause-specific mortality in 900,000 adults: collaborative analyses of 57 prospective studies. Lancet 2009;373:1083-96.

5. Phillips CM. Metabolically healthy obesity: personalised and public health implications. Trends Endocrinol Metabol 2016;27:189-91.

6. Bradshaw PT, Monda KL, Stevens J. Metabolic syndrome in healthy obese, overweight, and normal weight individuals: the Atherosclerosis Risk in Communities Study. Obesity (Silver Spring) 2013;21:203-9.

7. Fasshauer M, Blüher M. Adipokines in health and disease. Trends Pharmacol Sci 2015;36:461-70.

8. Kershaw EE, Flier JS. Adipose tissue as an endocrine organ. J Clin Endocrinol Metab 2004;89:2548-56.

9. Coelho M, Oliveira T, Fernandes R. Biochemistry of adipose tissue: an endocrine organ. Arch Med Sci 2013;9:191-200.

10. Gao X, Salomon C, Freeman DJ. Extracellular vesicles from adipose tissue - a potential role in obesity and type 2 diabetes? Front Endocrinol (Lausanne) 2017;8:202.

11. Vieira-Potter VJ. Inflammation and macrophage modulation in adipose tissues. Cell Microbiol 2014;16:1484-92.

12. Pellegrinelli V, Carobbio S, Vidal-Puig A. Adipose tissue plasticity: how fat depots respond differently to pathophysiological cues. Diabetologia 2016;59:1075-88.

13. Hansson GK, Libby P. The immune response in atherosclerosis: a double-edged sword. Nat Rev Immunol 2006;6:508-19.

14. Mathieu P, Poirier P, Pibarot, Lemieux I, Despres JP. Visceral obesity: the link among inflammation, hypertension, and cardiovascular disease. Hypertension 2009;53:577-84.

15. Bobryshev YV. Monocyte recruitment and foam cell formation in atherosclerosis. Micron 2006;37:208-22.

16. Gimbrone MA Jr, García-Cardeña G. Endothelial cell dysfunction and the pathobiology of atherosclerosis. Circ Res 2016;118:620-36.

17. Bhatt A, Rohatgi A. HDL cholesterol efflux capacity: cardiovascular risk factor and potential therapeutic target. Curr Atheroscler Rep 2016;18:2.

18. Maguire EM, Pearce SWA, Xiao Q. Foam cell formation: a new target for fighting atherosclerosis and cardiovascular disease. Vascul Pharmacol 2019;112:54-71.

19. Ley K, Miller YI, Hedrick CC. Monocyte and macrophage dynamics during atherogenesis. Arterioscler Thromb Vasc Biol 2011;31:150616.

20. Feig JE, Vengrenyuk Y, Reiser V, Wu C, Statnikov A, et al. Regression of atherosclerosis is characterized by broad changes in the plaque macrophage transcriptome. PLoS One 2012;7:e39790.

21. Moore, KJ, Sheedy FJ, Fisher EA. Macrophages in atherosclerosis: a dynamic balance. Nat Rev Immunol 2013;13:709-21.

22. Reiss AB, Anwar K, Merrill JT, Chan ES, Awadallah NW, et al. Plasma from systemic lupus patients compromises cholesterol homeostasis: a potential mechanism linking autoimmunity to atherosclerotic cardiovascular disease. Rheumatol Int 2010;30:591-8. 
23. Reiss AB, Wan DW, Anwar K, Merrill JT, Wirkowski PA, et al. Enhanced CD36 scavenger receptor expression in THP-1 human monocytes in the presence of lupus plasma: linking autoimmunity and atherosclerosis. Exp Biol Med (Maywood) 2009;234:354-60.

24. Reiss AB, Awadallah N, Malhotra S, Montesinos MC, Chan ESL, et al. Immune complexes and interferon- $\gamma$ decrease cholesterol 27-hydroxylase in human arterial endothelium and macrophages. J Lipid Res 2001;42:1913-22.

25. Reiss AB, Patel CA, Rahman MM, Chan ES, Hasneen K, et al. IFN-gamma impedes reverse cholesterol transport and promotes foam cell transformation in THP-1 human monocytes/macrophages. Med Sci Monit 2004;10:BR420-5.

26. Reiss AB. Effects of inflammation on cholesterol metabolism: impact on systemic lupus erythematosus. Curr Rheumatol Rep 2009; 11:255-60.

27. Voloshyna I, Modayil S, Littlefield MJ, Belilos E, Belostocki KB, et al. Plasma from rheumatoid arthritis patients promotes proatherogenic cholesterol transport gene expression in THP-1 human macrophages. Exp Biol Med (Maywood) 2013;238:1192-7.

28. Tan L, Liu L, Jiang Z, Hao X. Inhibition of microRNA-17-5p reduces the inflammation and lipid accumulation, and up-regulates ATPbinding cassette transporterA1 in atherosclerosis. J Pharmacol Sci 2019;139:280-8.

29. Choromańska B, Myśliwiec P, Choromańska K, Dadan J, Chabowski A. The role of CD36 receptor in the pathogenesis of atherosclerosis. Adv Clin Exp Med 2017;26:717-22.

30. Reardon CA, Lingaraju A, Schoenfelt KQ, Zhou G, Cui C, et al. Obesity and insulin resistance promote atherosclerosis through an IFN $\gamma$ regulated macrophage protein network. Cell Rep 2018;23:3021-30.

31. Zhu Y, Xian X, Wang Z, Bi Y, Chen Q, et al. Research progress on the relationship between atherosclerosis and inflammation. Biomolecules 2018;8:80.

32. Zhang L, Peppel K, Sivashanmugam P, Orman ES, Brian L, et al. Expression of tumor necrosis factor receptor-1 in arterial wall cells promotes atherosclerosis. Arterioscler Thromb Vasc Biol 2007;27:1087-94.

33. Howe KL, Fish JE. Transforming endothelial cells in atherosclerosis. Nat Metab 2019;1:856-7.

34. Yu XH, Zhang J, Zheng XL, Yang YH, Tang CK. Interferon- $\gamma$ in foam cell formation and progression of atherosclerosis. Clin Chim Acta 2015;441:33-43.

35. Hotamisligil GS. Inflammation and metabolic disorders. Nature 2006;444:860-7.

36. Hu D, Hannah J, Gray RS, Jablonski KA, Henderson JA, et al. Effects of obesity and body fat distribution on lipids and lipoproteins in nondiabetic american indians: the strong heart study. Obes Res 2000;8:411-21.

37. Franssen R, Monajemi H, Stroes ES, Kastelein JJ. Obesity and dyslipidemia. Med Clin North Am 2011;95:893-902.

38. Jellinger PS, Mehta AE, Smith DA, Handelsman Y, Ganda, O, et al.; AACE Task Force for Management of Dyslipidemia and Prevention of Atherosclerosis. American Association of Clinical Endocrinologists' Guidelines for management of dyslipidemia and prevention of atherosclerosis. Endocr Pract 2012;18:1-78.

39. Rashid S, Genest J. Effect of obesity on high-density lipoprotein metabolism. Obesity 2007;15:2875-88.

40. Klop B, Elte JW, Cabezas MC. Dyslipidemia in obesity: mechanisms and potential targets. Nutrients 2013;5:1218-40.

41. Grundy SM. Obesity, metabolic syndrome, and cardiovascular disease. J Clin Endocrinol Metab 2004;89:2595-600.

42. Fruchart JC, Sacks F, Hermans MP, Assmann G, Brown WV, et al. The Residual Risk Reduction Initiative: a call to action to reduce residual vascular risk in patients with dyslipidemia. Am J Cardiol 2008;102:1K-34K.

43. Kolovou GD, Anagnostopoulou KK, Cokkinos DV. Pathophysiology of dyslipidaemia in the metabolic syndrome. Postgrad Med J 2005;81:358-66.

44. Athyros VG, Tziomalos K, Karagiannis A, Mikhailidis DP. Dyslipidaemia of obesity, metabolic syndrome and type 2 diabetes mellitus: the case for residual risk reduction after statin treatment. Open Cardiovasc Med J 2011;5:24-34.

45. Ottaviani E, Malagoli D, Franceschi C. The evolution of the adipose tissue: a neglected enigma. Gen Comp Endocrinol 2011;174:1-4.

46. Després JP. Body fat distribution and risk of cardiovascular disease: an update. Circulation 2012;126:1301-13.

47. Van Dam AD, Boon MR, Berbee JFP, Rensen PCN, Van Harmelen V. Targeting white, brown and perivascular adipose tissue in atherosclerosis development. Eur J Pharmacol 2017;816:82-92.

48. Frühbeck G, Gómez-Ambrosi J, Muruzabal FJ, Burrell MA. The adipocyte: a model for integration of endocrine and metabolic signaling in energy metabolism regulation. Am J Physiol Endocrinol Metab 2001;280:E827-47.

49. Ouchi N, Parker JL, Lugus JJ, Walsh K. Adipokines in inflammation and metabolic disease. Nat Rev Immunol 2011;11:85-97.

50. Liberale L, Bonaventura A, Vecchiè A, Casula M, Dallegri F, et al. The role of adipocytokines in coronary atherosclerosis. Curr Atheroscler Rep 2017;19:10.

51. Blüher, M. Adipose tissue dysfunction in obesity. Exp Clin Endocrinol Diabetes 2009;117:241-50.

52. Ohman MK, Shen Y, Obimba CI, Wright AP, Warnock M, et al. Visceral adipose tissue inflammation accelerates atherosclerosis in apolipoprotein E-deficient mice. Circulation 2008;117:798-805.

53. Pollack RM, Donath MY, LeRoith D, Leibowitz G. Anti-inflammatory agents in the treatment of diabetes and its vascular complications. Diabetes Care 2016;39:S244-52.

54. O’Donoghue ML, Braunwald E, White HD, Lukas MA, Tarka E, et al. Effect of darapladib on major coronary events after an acute coronary syndrome: the SOLID-TIMI 52 randomized clinical trial. JAMA 2014;312:1006-15.

55. Reiss AB, Vernice NA, Siegart NM, De Leon J, Kasselman LJ. Exosomes in cholesterol metabolism and atherosclerosis. Cardiovasc Hematol Disord Drug Targets 2017;17:185-94.

56. Hoeke G, Kooijman S, Boon MR, Rensen PCN, Berbée JF. Role of Brown fat in lipoprotein metabolism and atherosclerosis. Circ Res 2016;118:173-82.

57. Xiong W, Zhao X, Villacorta L, Rom O, Garciabarrio MT, et al. Brown adipocyte-specific PPAR $\gamma$ (peroxisome proliferator-activated 
receptor $\gamma$ ) deletion impairs perivascular adipose tissue development and enhances atherosclerosis in mice. Arterioscler Thromb Vasc Biol 2018;38:1738-47.

58. Nedergaard J, Bengtsson T, Cannon B. Unexpected evidence for active brown adipose tissue in adult humans. Am J Physiol Endocrinol Metab 2007;293:E444-52.

59. Cypess AM, Lehman S, Williams G, Tal I, Rodman D, et al. Identification and importance of brown adipose tissue in adult humans. N Engl J Med 2009;360:1509-17.

60. Bartelt A, Bruns OT, Reimer R, Hohenberg H, Ittrich H, et al. Brown adipose tissue activity controls triglyceride clearance. Nat Med 2011;17:200-5.

61. Liu X, Zheng Z, Zhu X, Meng M, Li L, et al. Brown adipose tissue transplantation improves whole-body energy metabolism. Cell Res 2013;23:851-4.

62. Geerling JJ, Boon MR, van der Zon GC, van den Berg SA, van den Hoek AM, et al. Metformin lowers plasma triglycerides by promoting VLDL-triglyceride clearance by brown adipose tissue in mice. Diabetes 2014;63:880-91.

63. Tanyanskiy DA, Pigarevskii PV, Maltseva SV, Denisenko AD. Immunohistochemical analysis of adiponectin in atherosclerotic lesions of human aorta. ARYA Atheroscler 2019;15:179-84.

64. Achari AE, Jain SK. Adiponectin, a therapeutic target for obesity, diabetes, and endothelial dysfunction. Int J Mol Sci 2017;18:1321.

65. Magni P, Liuzzi A, Ruscica M, Dozio E, Ferrario S, et al. Free and bound plasma leptin in normal weight and obese men and women: relationship with body composition, resting energy expenditure, insulin-sensitivity, lipid profile and macronutrient preference. Clin Endocrinol (Oxf) 2005;62:189-96.

66. Hartwig S, De Filippo E, Göddeke S, Knebel B, Kotzka J, et al. Exosomal proteins constitute an essential part of the human adipose tissue secretome. Biochim Biophys Acta Proteins Proteom 2019;1867:140172.

67. Phoonsawat W, Aoki-Yoshida A, Tsuruta T, Sonoyama K. Adiponectin is partially associated with exosomes in mouse serum. Biochem Biophys Res Commun 2014;448:261-6.

68. Lee JE, Moon PG, Lee IK, Baek MC. Proteomic analysis of extracellular vesicles released by adipocytes of otsuka long-evans tokushima fatty (OLETF) rats. Protein J 2015;34:220-35.

69. Raposo G, Stoorvogel W. Extracellular vesicles: exosomes, microvesicles, and friends. J Cell Biol 2013;200:373-83.

70. Shah R, Patel T, Freedman JE. Circulating extracellular vesicles in human disease. N Engl J Med 2018;379:2180-1.

71. Haraszti RA, Didiot MC, Sapp E, Leszyk J, Shaffer SA, et al. High-resolution proteomic and lipidomic analysis of exosomes and microvesicles from different cell sources. J Extracell Vesicles 2016;5:32570.

72. Trajkovic K, Hsu C, Chiantia S, Rajendran L, Wenzel D, et al. Ceramide triggers budding of exosome vesicles into multivesicular endosomes. Science 2008;319:1244-7.

73. Skotland T, Hessvik NP, Sandvig K, Llorente A. Exosomal lipid composition and the role of ether lipids and phosphoinositides in exosome biology. J Lipid Res 2019;60:9-18.

74. Yoon Y, Kim O, Gho Y. Extracellular vesicles as emerging intercellular communicasomes. BMB Rep 2014;47:531-9.

75. O’Brien J, Hayder H, Zayed Y, Peng C. Overview of microRNA biogenesis, mechanisms of actions, and circulation. Front Endocrinol 2018;9:402.

76. Dini L, Tacconi S, Carata E, Tata AM, Vergallo C, et al. Microvesicles and exosomes in metabolic diseases and inflammation. Cytokine Growth Factor Rev 2020;51:27-39.

77. Colombo M, Raposo G, Théry C. Biogenesis, secretion, and intercellular interactions of exosomes and other extracellular vesicles. Annu Rev Cell Dev Biol 2014;30:255-89.

78. Chen Y, Buyel JJ, Hanssen MJ, Siegel F, Pan R, et al. Exosomal microRNA miR-92a concentration in serum reflects human brown fat activity. Nat Commun 2016;27;7:11420.

79. Thomou T, Mori MA, Dreyfuss JM, Konishi M, Sakaguchi M, et al. Adipose-derived circulating miRNAs regulate gene expression in other tissues. Nature 2017;542:450-5.

80. Ortega FJ, Moreno M, Mercader JM, Moreno-Navarrete JM, Fuentes-Batllevell N, et al. Inflammation triggers specific microRNA profiles in human adipocytes and macrophages and in their supernatants. Clin Epigenetics 2015;7:49.

81. Ortega FJ, Mercader JM, Moreno-Navarrete JM, Nonell L, Puigdecanet E, et al. Surgery-induced weight loss is associated with the downregulation of genes targeted by microRNAs in adipose tissue. J Clin Endocrinol Metab 2015;100:E1467-76.

82. Ferrante SC, Nadler EP, Pillai DK, Hubal MJ, Wang Z, et al. Adipocyte-derived exosomal miRNAs: a novel mechanism for obesityrelated disease. Pediatr Res 2015;77:447-54.

83. Chartoumpekis DV, Zaravinos A, Ziros PG, Iskrenova RP, Psyrogiannis AI, et al. Differential expression of microRNAs in adipose tissue after long-term high-fat diet-induced obesity in mice. PLoS One 2012;7:e34872.

84. Chang W, Wang J. Exosomes and their noncoding RNA cargo are emerging as new modulators for diabetes mellitus. Cells 2019;8:E853.

85. Mori MA, Thomou T, Boucher J, Lee KY, Lallukka S, et al. Altered miRNA processing disrupts brown/white adipocyte determination and associates with lipodystrophy. J Clin Invest 2014;124:3339-51.

86. Ying W, Riopel M, Bandyopadhyay G, Dong Y, Birmingham A, et al. Adipose tissue macrophage-derived exosomal miRNAs can modulate in vivo and in vitro insulin sensitivity. Cell 2017;171:372-84.e12.

87. Chen Y, Pfeifer A. Brown fat-derived exosomes: small vesicles with big impact. Cell Metab 20174;25:759-60.

88. Fisher FM, Kleiner S, Douris N, Fox EC, Mepani RJ, et al. FGF21 regulates PGC-1 $\alpha$ and browning of white adipose tissues in adaptive thermogenesis. Genes Dev 2012;26:271-81.

89. Kokkinos J, Tang S, Rye KA, Ong KL. The role of fibroblast growth factor 21 in atherosclerosis. Atherosclerosis 2017;257:259-65. 
90. Deng ZB, Poliakov A, Hardy RW, Clements R, Liu C, et al. Adipose tissue exosome-like vesicles mediate activation of macrophageinduced insulin resistance. Diabetes 2009;58:2498-505.

91. Curtiss LK, Tobias PS. Emerging role of toll-like receptors in atherosclerosis. J Lipid Res 2009;50:S340-5.

92. Xie Z, Wang X, Liu X, Du H, Sun C, et al. Adipose-derived exosomes exert proatherogenic effects by regulating macrophage foam cell formation and polarization. J Am Heart Assoc 2018;7:e007442.

93. Voloshyna I, Reiss AB. The ABC transporters in lipid flux and atherosclerosis. Prog Lipid Res 2011;50:213-24.

94. Barberio MD, Kasselman LJ, Playford MP, Epstein SB, Renna HA, et al. Cholesterol efflux alterations in adolescent obesity: role of adipose-derived extracellular vesical microRNAs. J Transl Med 2019;17:232.

95. Crewe C, Joffin N, Rutkowski JM, Kim M, Zhang F, et al. An endothelial-to-adipocyte extracellular vesicle axis governed by metabolic state. Cell 2018;175:695-708.

96. Zhao Q, Yang J, Liu B, Huang F, Li Y. Exosomes derived from mangiferin-stimulated perivascular adipose tissue ameliorate endothelial dysfunction. Mol Med Rep 2019;19:4797-805.

97. Kita S, Maeda N, Shimomura I. Interorgan communication by exosomes, adipose tissue, and adiponectin in metabolic syndrome. J Clin Invest 2019;129:4041-9.

98. Summerhill V, Orekhov A. Pericytes in atherosclerosis. Adv Exp Med Biol 2019;1147:279-97.

99. Orekhov AN, Bobryshev YV, Chistiakov DA. The complexity of cell composition of the intima of large arteries: focus on pericyte-like cells. Cardiovasc Res 2014;103:438-51.

100. Liu C, Ge HM, Liu BH, Dong R, Shan K, et al. Targeting pericyte-endothelial cell crosstalk by circular RNA-cPWWP2A inhibition aggravates diabetes-induced microvascular dysfunction. Proc Natl Acad Sci U S A 2019;116:7455-64.

101. Pan Y, Hui X, Hoo RLC, Ye D, Chan CYC, et al. Adipocyte-secreted exosomal microRNA-34a inhibits M2 macrophage polarization to promote obesity-induced adipose inflammation. J Clin Invest 2019;129:834-49.

102. Ogawa R, Tanaka C, Sato M, Nagasaki H, Sugimura K, et al. Adipocyte-derived microvesicles contain RNA that is transported into macrophages and might be secreted into blood circulation. Biochem Biophys Res Commun 2010;398:723-9.

103. Eguchi A, Lazic M, Armando AM, Phillips SA, Katebian R, et al. Circulating adipocyte-derived extracellular vesicles are novel markers of metabolic stress. J Mol Med (Berl) 2016;94:1241-53.

104. Kobayashi Y, Eguchi A, Tempaku M, Honda T, Togashi K, et al. Circulating extracellular vesicles are associated with lipid and insulin metabolism. Am J Physiol Endocrinol Metab 2018;315:E574-82.

105. Hubal MJ, Nadler EP, Ferrante SC, Barberio MD, Suh JH, et al. Circulating adipocyte-derived exosomal MicroRNAs associated with decreased insulin resistance after gastric bypass. Obesity (Silver Spring) 2017;25:102-10.

106. Zhao H, Shang Q, Pan Z, Bai Y, Li Z, et al. Exosomes from adipose-derived stem cells attenuate adipose inflammation and obesity through polarizing M2 macrophages and beiging in white adipose tissue. Diabetes 2018;67:235-47.

107. Chistiakov DA, Kashirskikh DA, Khotina VA, Grechko AV, Orekhov AN. Immune-inflammatory responses in atherosclerosis: the role of myeloid cells. J Clin Med 2019;8:1798.

108. Lu Z, Wang F, Yu P, Wang X, Wang Y, et al. Inhibition of miR-29b suppresses MAPK signaling pathway through targeting SPRY1 in atherosclerosis. Vascul Pharmacol 2018;102:29-36. 